\title{
Journal of the American Medical Association.
}

\author{
EDITED UNDER THE DIRECTION OF THE BOARD OF TRUSTEES.
}

\author{
PUBLISHED WEEKLY.
}

VoL. XIII.

CHICAGO, JULY 20, 1889.

No. 3 .

\section{ADDRESSES.}

\section{CONSIDERATIONS CONCERNING SOME EXTERNAL, SOURCES OF INFECTION IN THEIR BEARING ON PRE- VENTIVE MEDICINE.}

Being the Addiess on State Medicine delizered before the American Medical Association, in Neaport, on June 28,1889 .

BY WM. H. WELCH, M.D., PROFESSOK OF PATHOLOGY, JOHNS HOPKINS UNIVERSITY,

No department of medicine has been cultivated in recent years with such zeal and with such fruitful results, as that relating to the causes of infectious diseases. The most important of these results for preventive medicine, and for the welfare of mankind is the knowledge that a large proportion of the causes of sickness and death are removable.

It is evident that efforts to preserve health will be most intelligently and effectually applied when they are based upon an accurate and full knowledge of the agencies which cause disease. Public and private hygiene, however, can not, and fortunately has not, waited for the full light of that day whose dawn has only begun to appear, when we shall have a clear insight into the causation of preventable diseases. Cleanliness and comfort demand that means shall be taken to render pure the ground on which we live, the air which we breathe, and the water and food with which we are supplied, and we must meet these needs without waiting to learn just what relation infectious agents bear to the earth, air, water and food.

It is a fortunate circumstance that modern sanitation has been controlled so largely by the belief in the dependence of endemic and epidemic diseases upon organic impurities in the soil and in the water. Incomplete and even erroneous in many respects, as are the views which have prevailed concerning the origin and spread of epidemic diseases by the decomposition of organic substances, the sanitary measures which have been directed toward the removal of filth have achieved great conquests in limiting the development and extension of many infectious diseases.
The benefits which one Commonwealth of this country has derived from the intelligent employment of public sanitary measures were clearly and forcibly presented before this Association last year by Dr. Walcott in his admirable Address on State Medicine.

While nothing should be said, or need be said, to lessen the importance of cleanliness for public health, it is important to bear in mind, that hygienic cleanliness and æsthetic cleanliness are not identical. In water which meets the most severe chemical tests of purity typhoid bacilli have been found. On the other hand, the air in the Berlin sewers, which certainly does not meet the most modest demands of æsthetic cleanliness, has been found to be nearly or quite free from bacteria.

It needs only to be stated to be generally admitted that the scientific basis of preventive medicine must be the accurate knowledge of the causative agents of preventable diseases, a knowledge which can be derived only from a careful study of all of the properties of these agents, the modes of their reception and of their elimination by the body, the circumstances which favor, and those which retard or prevent their development and spread, their behavior in the various substances which surround us, or which we take into our bodies and the sources of infection, not only those which laboratory experiments show to be possible, but those which are actually operative.

So long as we were unacquainted with the living organisms causing infection, the means at our disposal for studying the etiology of infectious diseases were linited to the observation of all of the circumstances which we could determine regarding the origin and spread of these diseases. We could only infer what might be the properties of the infectious agents from the study of phenomena often obscure and difficult of interpretation. Chiefly by this method of investigation the science of epidemiology has been built up. It has established facts and laws no less of practical than of scientific importance. But it has left unsolved many problems, and has filled gaps with speculations. Admitted epidemiological facts are often open to various interpretations.

We are evidently at a great advantage when we can study the epidemiological facts with a knowledge of the substances which actually cause in- 
fection, and this we are now enabled to do for a limited number of the infectious diseases. This new method of research, which thus far has been mainly bacteriological, has aided us not so much by simplifying the problems of etiology, which still remain complicated enough, as by affording greater accuracy to the results.

It is my aim in this address to consider some results of the modern studies of pathogenic microorganisms in their bearing upon preventive medicine, more particularly upon the sources of infection. It is, of course, impossible within the limits of the address, to attempt a complete survey of this important field. Time will permit the presentation of only some of the salient points.

Infectious diseases are those which are caused by the multiplication within the body of pathogenic microörganisms.

It has always been recognized that some infectious diseases, such as the exanthematous fevers, are conveyed directly from the sick to the healthy. It is not disputed that in these, evidently contagious diseases, the infectious germ is discharged from the body in a state capable at once of giving rise to infection.

In a second group of infectious diseases, of which malaria is the type, the infected individual neither transmits the disease to another person, nor, so far as we know, is capable of infecting a locality. Here there is a reason to believe that the infectious germ is not thrown off in a living state from the body, but is destroyed within the body. In this group the origin of infection under natural conditions is always outside of the body.

In a third group there is still dispute whether the disease can be transmitted directly from person to person, but all are agreed that the infected individual can infect a locality. It is especially fortunate that the bacteria which cause cholera and typhoid fever, the two most iusportant representatives of this group of so-called miasmaticcontagious diseases, have been discovered and isolated in pure culture. These are the diseases about whose origin and epidemic extension there has been the greatest controversy. They, above all other diseases, have given the impulse to public sanitation during the last half century. The degree of success with which their extension in a community is prevented is an important gauge of the excellence of the local sanitary arrangements. A clear comprehension of the origin and spread of these diseases signifies the solution of many of the most vexed and important problems of epidemiology and of State hygiene.

It is difficult to understand how those who accept the discovery that the bacteria causing typhoid fever and cholera, have been found and cultivated from the stools of patients affected with these diseases, can doubt that these patients are possible sources of contagion; or can entertain the view once so widely prevalent that the infectious germs of these diseases are discharged from the body in a condition incapable of producing immediate infection. In an address delivered on another occasion, I have endeavored to present the consideration which reconcile the comparative infrequency of direct contagion for these diseases, with the belief in the elimination of the causative germs in an active state from the body, and have there pointed out several well known factors which determine the frequency of conveyance of an infectious disease by contagion. There are reasons, some of them very obvious, why diseases in which the infectious substances are operative only when received into the digestive tract, and are discharged usually only with the feces, are less likely to be transmitted by immediate contagion than those diseases in which the virus is thrown off from the skin on epidermal scales.

But the field of operation of direct contagion for these so-called miasmatic-contagious diseases is at most a restricted one, and the chief sources of infection are outside of the body from which primarily the infectious germs may have been derived. It is to these external sources of infection, which are of such importance in public hygiene, that I wish especially to direct attention.

A full comprehension of the sources of infection is, of course, to be obtained only by a detailed study of the etiology of the individual infectious diseases, but this is, of course, impossible within the limits of an address. It may, however, be useful to present some of the facts which have a general bearing upon the subject. Let us consider, then, from the point of view of modern bacteriological studies, what rôle in harboring or transporting infectious agents, may be played by those substances or media with which we necessarily come into intimate contact, such as the air, the ground, the water and our food.

It is universally admitted that many infectious agents may be transported by the air, but the extent of danger from this source has often been exaggerated. It is a popular error to suppose that most of the minute particles of dust in the air either are or contain living organisms. The methods for determining the number, and kind of bacteria and fungi in the air, are now fairly satisfactory, although by no means perfect. These have shown that while the number of living bacteria and fungi in the atmosphere, in and around human habitations cannot be considered small, still it is greatly inferior to that in the ground or in most waters. Unlike fungus spores, bacteria do not seem to occur to any extent in the air as single detached particles, which would then necessarily be extremely minute, but rather in clumps or attached to particles of dust of relatively large size. As a result in a perfectly quiet atmosphere, these comparatively heavy particles which contain bacteria, rapidly settle to the ground or upon 
underlying objects, and are easily filtered out by passing the air through porous substances, such as cotton-wool or sand. Rain washes down a large number of bacteria from the air. That the air bacteria are derived from the ground or objects upon it is shown by their total absence, as a rule, from sea air at a distance from land, this distance naturally varying with the clirection and strength of the wind.

A fact of capital importance in understanding the relations of bacteria to the air, and one of great significance for preventive medicine, is the impossibility of currents of air detaching bacteria from moist surfaces. Substances containing pathogenic bacteria, as, for instance, sputum containing tubercle bacilli or excreta holding typhoid bacilli, can not, therefore, infect the air unless these substances first becone dry and converted into a fine powder. We are able to understand why the expired breath is free from bacteria and cannot convey infection, except as little particles may be mechanically detached by acts of coughing, sneezing or hawking. Those bacteria, the vitality of which is rapidly destroyed by complete desiccation, such as those of Asiatic cholera, evidently are not likely to be transported as infectious agents by the air, if we except such occasional occurrences as their conveyance for a short distance in spray.

The only pathogenic bacteria which hitherto have been found in the air, are the pus organisms, including the streptococcus, found by Prudden in a series of cases of diphtheria, and tubercle bacilli, but no far-reaching conclusions can be drawn from the failure to find other infectious organisms when we consider the imperfection of our methods, and the small number of observations directed to this point. The evidence in other ways is conclusive that many infectious agents-and here the malarial germ should be prominently mentioned - can be, and often are, conveyed by the air. While we are inclined to restrict within narrower limits than has been customary the danger of infection through the air, we must recognize that this still remains an important source of infection for many diseases. All those, however, who have worked practically with the cultivation of microörganisms, have come to regard contact with infected substances as more dangerous than exposure to the air, and the same lesson may be learned from the methods which modern surgeons have found best adapted to prevent the infection of wounds with the cosmopolitan bacteria, which cause suppuration.

We are not,. of course, to suppose that infectious germs floating in the form of dust in the atmosphere are dangerous, only from the possibility of our drawing them in with the breath. Such germs may be deposited on substances with which we readily come into contact, or they may fall on articles of food where they may find conditions suitable for their reproduction, which cannot occur when they are suspended in the air in consequence of the lack of moisture.

From the facts which have been mentioned concerning the relations of bacteria to the air, what points of view present themselves to guide us in preventing infection through this channel? Surely something more than that this purpose is accomplished simply by abolishing foul odors.

Certain indications are so plain as to need only to be mentioned in this connection, such as the disinfection and removal, as far as possible, of all infected substances, an indication which applies equally to all channels of infection, and which it is much easier to mention than it is to describe how it shall be realized. But there are two indications which apply especially to the prevention of the transportation of disease germs by the air. One is the necessity of guarding, so far as practicable, against the desiccation, when exposed to the air, of substances which contain infectious germs not destroyed by drying, and another is free ventilation.

For no disease is the importance of the first of these indications so evident and so well established as for tuberculosis, the most devastating of all infectious diseases. Against this disease, formidable as it may seem to cope with it, the courageous crusade of preventive medicine has begun, and is destined to continue.

It is now generally recognized that the principal, although not the sole, sources of tuberculous infection are the sputum of individuals affected with pulmonary tuberculosis and the milk of tuberculous cows. Cornet, who has made a laborious and most instructive experimental study of the modes and dangers of infection from tuberculous sputum, has also elaborated the practical measures which should be adopted to diminish or annihilate these dangers. These measures have been so recently and so widely published in medical journals, and so clearly presented before a Section of this Association, that I mention them only to call the attention of practitioners of medicine to their importance, and to emphasize the fact that they are based chiefly upon the principle that infectious substances of such nature as tuberculous sputum should not be allowed to become dry and converted into dust wben exposed to the air.

By means of free ventilation, disease-producing microörganisms which may be present in the air of rooms, are carried away and distributed so far apart that the chance of infection from this source is removed or reduced to a minimum. It is a well-established clinical observation that the distance through which the specific microbes of sucl diseases as small-pox or scarlatina are likely to be carried from the patient by the air, in such concentration as to cause infection, is small, usually not more than a few feet, but increases by 
crowding of patients and absence of free ventilation. The well-known experiences in the prophylaxis and treatment of typhus fever are a forcible illustration of the value of free ventilation.

It is, of course, not to be understood that by ventilation we accomplish the disinfection of a house or apartment. Ventilation is only an adjunct of such disinfection which, as already mentioned, is of first importance. Time will not permit, nor is it in the plan of this address, to discuss the details of such questions as house disinfection, but I may be permitted to say that the methods for disinfecting apartments have been worked out on a satisfactory experimental basis, and should be known, at least, by all public health officers. Whether it be pertinent to this occasion or not, I cannot forbear to add my protest to that of others against placing reliance upon any method hitherto employed of disinfecting houses or apartments by fumigation. And I would, furthermore, call attention to the lack in most cities of this country of public disinfecting establishments, such as are in use with excellent results in many cities of Europe, and which are indispensable for the thorough and convenient disinfection of clothing, bedding, carpets, curtains, etc.

After this short digression let us pass from the consideration of the air as a carrier of infection to another important external source of infection, namely, the ground. That the prevalence of many infectious diseases depends upon conditions pertaining to the soil cannot be qestioned, but the nature and the extent of this influence have been and are the subjects of lively discussion. The epidemiological school led by Pettenkofer, assigns as is well-known, to the ground the chief, and even a specific and indispensable influence in the spread of many epidemic diseases, particularly clolera and typhoid fever. The statistics, studies and speculations of epidemiologists which have related to this subject, probably surpass in number and extent those concerning any other epidemiological factor. The exclusive ground hypothesis has become an ingenious and carefully elaborated doctrine with those who believe that such diseases as cholera and typhoid fever can never be transmitted by contagion. These authorities cling to this doctrine with a tenacity which indicates that on it depends the survival of the exclusively localistic dogma for these diseases.

To all who have not held aloof from modern bacteriological investigations, it must be clear that views which have widely prevailed concerning the relations of many infectious germs to the soil require revision. The question is still a difficult and perplexing one, but on some hitherto obscure or misunderstood points these investigations have shed light, and from the same source we may expect further important contributions to a comprehension of the relations of the ground to the development of infectious diseases.

The ground, unlike the air, is the resting or the breeding place of a vast number of species of microörganisms, including some which are pathogenic. Instead of a few bacteria or fungi in a liter as with the air, we find in most specimens of earth thousands, and often hundreds of thousands of microörganisms in a cubic centimeter. Fraenkel found the virgin soil almost as rich in bacteria and fungi as that around human habitations.

'This vast richness in microörganisms belongs, however, only to the superficial layers of the earth. Where the ground has not been greatly disturbed by human hands, there is, as a rule, about three to five feet below the surface an abrupt diminution in the number of living organisms, and at the depth where the sub-soil water usually lies, bacteria and fungi have nearly or entirely disappeared. Fraenkel, who first observed this sudden diminution in the number of microorganisus at a certain level beneath the surface, explains this singular fact by the formation at this level of that sticky accumulation of fine particles consisting largely of bacteria which forms the efficient layer in large sand filters for water. Of course the number of bacteria, and the depth to which they penetrate, will vary somewhat with the character, especially the porosity of the soil and its treatment, but the important fact that all, or nearly all of the bacteria and fungi are retained in the ground above the level of the sub-soil water, will doubtless hold true for most situations.

The conditions are not favorable for the multiplication of bacteria in the depth of the ground, as is shown by the fact that in specimens of earth brought to the surface from a depth of a few feet, the bacteria which are at first present, rapidly multiply. What all of the conditions are which prevent the reproduction of bacteria in the deep soil has not been ascertained, but the fact necessitates similar precautions in the bacteriological examination of the soil as in that of water.

We have but meagre information as to the kinds of bacteria present in the ground in comparison with their vast number. Many of those which have been isolated and studied in pure culture possess but little interest for us so far as we know. To some of the microörganisms in the soil appears to be assigned the rôle of reducing or of oxidizing highly organized substances to the simple forms required for the nutrition of plants. We are in the habit of considering so much the injurious bacteria that it is pleasant to contemplate this beneficent function, so essential to the preservation of life on this globe.

Among the pathogenic bacteria which have their natural home in the soil the most widely distributed are the bacilli of malignant œdema and those of tetanus. I have found some garden earth in Baltimore extremely rich in tetanus bacilli, so that the inoculation of animals in the Downloaded From: http://jama.jamanetwork.com/ by a University of Manitoba User on 06/14/2015 
laboratory with small bits of this earth rarely fails to produce tetanus. In infected localities the anthrax bacillus and in two instances the typhoid bacillus, so far as it was possible to identify it, have been discovered in the earth. There is reason to believe that other germs infectious to human beings may have their abiding place in the ground; certainly no one doubts that the malarial germ lives there. As the malarial germ has been shown to be an organism entirely different from the bacteria and the fungi, we cannot apply directly to its behavior in the soil and its transportation by the air, facts which have been ascertained only for the latter species of microörganisms, and the same precautions must be observed for other diseases with whose agents of infection we are not acquainted, as, for instance, yellow fever.

In view of the facility with which infectious germs derived from human beings or animals may gain access to the soil, it becomes a matter of great importance to determine how far such germs find in the soil conditions favorable for their preservation or their growth. We have, as is well known, a number of epidemiological observations bearing upon this subject, but with few exceptions these can be variously interpreted, and it is not my purpose to discuss them. The more exact bacteriological methods can, of course, be applied only to the comparatively small number of infectious diseases the causative germs of which have been isolated and cultivated, and these methods hitherto have been applied to this question only imperfectly. We cannot regard the soil as a definite and unva. rying substance in its chemical, physical and biodogical properties. What has been found true of one kind of soil may not be so of another. Moreover, we cannot in our experiments bring together all of the conditions in nature which may have a bearing on the behavior of specific microörganisms in the soil. We must, therefore, be cautious in coming to positive conclusions on this point on the basis of experiments, especially those with negative result. With these cautions kept constantly in mind the question, however, is one eninently open to experimental study.

The experiments which have thus far been made to determine the behavior of infectious microörganisms in the ground have related especially to the bacilli of anthrax, of typhoid fever and of cholera, and, fortunately, these are the diseases about whose relations to the ground there has been the most discussion, and concerning which we are most eager to acquire definite information.

As regards anthrax bacilli, it has been determined that in ordinary garden or field earth they do not multiply, but in earth contaminated by blood, urine or fæces their reproduction can occur. They can grow on various vegetable substrata. There is no reason to doubt, therefore, that the anthrax bacilli can find in or on the ground suitable conditions for their multiplication, although such conditions are not everywhere present. For durable infection of the soil with anthrax bacilli it is, however, more important that these bacilli should find there suitable conditions for the formation of spores, than that they should be able simply to multiply. The vegetable forms of anthrax bacilli would not, as a rule, be able to survive for any great length of time the hostile influences which they are likely to encounter in the ground, such as insufficient or exhausted nutriment, absence of sufficient moisture and the attacks of saprophytic organisms. On the other hand, against these injurious influences the anthrax spores have great resistance. In the superficial layers of the ground the anthrax bacilli may often find those conditions of moisture, of temperature, of oxygen supply and of insufficient food which we know are most favorable for the development of their spores; indeed, Soyka has shown that the ground presents often these conditions better than our culture media. A circumstance discovered by Feltz, which, however, needs confirmation, is, if true, of not little significance. He finds that anthrax bacilli may undergo a progressive diminution in virulence in the soil. It this should be true likewise of other infectious microörganisms, we should be able to account in some instances for the variable degree of virulence which clinical observation indicates that certain agents of infection acquire. So far as anthrax bacilli are concerned, we may conclude, therefore, that the ground occasionally offers suitable conditions for their reproduction, but what is of greater importance, it offers especially favorable conditions for their long-continued preservation in the form of spores. I must forego here the further consideration of the special circumstances inherent in the soil which control the origin and spread of epidemics of anthrax in cattle, although many interesting investigations have been directed to this subject.

Of greater interest to physicians is the behavior of typhoid and of cholera bacteria in the ground. As has already been intimated, the ground is regarded by Pettenkofer and his school as the principal breeding-place of these microörganisms outside of the body. This view, however, is not supported by bacteriological investigations. Inasmuch as the cholera and typhoid bacilli may multiply on various vegetable substrata and substances derived from animals at temperatures often present in the ground, it is evident that here and there conditions may be present for their growth in the ground, but this growth is likely to be soon interrupted by the invasion of ordinary saprophytic organisms and other harmful influences. The typhoid bacilli are more hardy in resisting these invaders than are the cholera bacteria, which easily succumb, but even for the former, so far as our present knowledge extends, the ground can rarely serve as a favorable breeding-place. 
It is not, however, necessary that these organisms should multiply in order to infect for a considerable time the ground; it is sufficient if their vitality is preserved. As to this latter point, the reports of different investigators are not altogether concordant. Such excellent observers as Koch, Kitasato and Uffelmann found that the cholera bacteria, when added to fæces or a mixture of fæces and urine, rapidly diminished in number and, at the end of three or four days at the most, had wholly disappeared. In a mixture of the intestinal contents from a cholera corpse with earth and water Koch found numerous cholera bacteria at the end of three days, but none at the end of five days. On the other hand, Gruber reports the detection of cholera bacteria in cholera dejecta fifteen days old. The weight of bacteriological evidence, therefore, is opposed to the supposition that the bacteria of Asiatic cholera preserve their vitality for any considerable time in the ground or in the excreta.

With respect to the bacilli which cause typhoid fever, it has been shown by Uffelmann that these may live in fæces, mixture of fæces and urine, and mixture of garden earth, fæces and urine for at least four and five months, and doubtless longer, although they may die at the end of a shorter period. He also finds that, under these apparently unfavorable conditions, some multiplication of the bacilli may occur, although not to any considerable extent. Grancher and Deschamps found that typhoid bacilli may live in the soil for at least five months and a half. Unlike the cholera bacteria, therefore, the typhoid bacilli may exist for months at least in the ground and in fæcal matter, holding their own against the growtl of multitudes of saprophytes. This difference in the behavior of cholera and of typhoid germs is in harmony with clinical experience.

As regards other infectious bacteria than those which have been considered I shall only mention that tubercle bacilli, although incapable of multiplication under the ordinary conditions of nature outside of the body, may preserve their vitality for a long period in the ground, on account of their resistant character; and furthermore, that the pyogenic cocci, on account of their considerably resistant nature and their modest demands in the way of nutriment, can be preserved and sometimes, probably, grow in the ground. Indeed, the staphylococcus pyogenes aureus has been found in the earth by Liubbert.

The conclusion which we may draw from the observations mentioned is that, in general, the soil is not a good breeding-place for most of the infectious bacteria with which we are acquainted, but that it can retain for a long time with unimpaired vitality those which produce spores or which offer considerable resistance to injurious agencies, such as anthrax bacilli, typhoid bacilli, tubercle bacilli and the pyogenic cocci.
In order to become infected with bacteria in or on the ground these bacteria must in some way be introduced into the body ; and we must, therefore, now attempt to determine how bacteria may be transported to us from the ground. So various and intricate are the possibilities for this transportation that it is hopeless to attempt to specify them all.

There occurs to us first the possibility of the conveyance of infectious microörganisms from the soil by means of currents of air, a mode of carrying infection which has already been considered, Here I shall only repeat that the wind can remove bacteria from the ground only when the surface is dry and presents particles of dust, and that the sole, and perhaps the chief, danger is not that we may inhale the infected dust.

Manifold are the ways in which we may be brought into contact with infectious bacteria in the ground, either directly or by means of vegetables to which particles of earth are attached, by the intervention of domestic animals, by the medium of flies or other insects, and in a variety of other ways, more or less apparent.

An important, doubtless for some diseases the most important, medium of transportation of bacteria from an infected soil is the water which we drink or use for domestic purposes. From what has been said it is evidently not the subsoil water which is dangerous, for infectious like other bacteria cannot generally reach this in a living state, but the danger is from the surface water and from that which trickles through the upper layers of the ground, as well as from that which escapes from defective drains, gutters, cesspools, privy vaults and wrongly constructed sewers or improper disposal of sewage. I shall have something to say presently of water as a source of infection and shall not further elaborate here the dangers of infection of drinking-water through contaminated soil, dangers which, especially as regards typhoid fever, are widely appreciated in this country, even if often imperfectly counteracted.

A point which has been much discussed, and one of interest, is whether bacteria which are in the depths of the ground can come to the surface. Two agencies especially have been considered by some as capable of transporting bacteria from the depth to the surface. One is ascending currents of air in the ground and the other is the capillarity of fluids in the minute pores of the ground. The first of these suspected agencies must be unquestionably rejected in view of the fact that even a few inches of sand is sufficient to filter all of the bacteria out of the air, even when it is in much more rapid motion than can occur within the ground. Moreover, that degree of dryness which is essential for the detachment of bacteria by aircurrents is not likely to be present much below the surface of the ground. The experiments 
which have been made to determine to what extent bacteria may be carried upward by the capillarity of fluids in the ground have not yielded harmonious results, but the weight of evidence is opposed to the belief that this is a factor of any considerable importance for this purpose.

From what has been said concerning the growth of pathogenic bacteria in the soil we shall not be inclined to attribute to the multiplication and the motility of these organisms much influence in changing their place in the ground.

The somewhat sensational rôle assigned by Pasteur to earth worms of bringing bacteria to the surface cannot be wholly ignored and has received support from observations of Bollinger regarding anthrax, but it is questionable whether much importance is to be attached to this agency.

Regarding the depth to which typhoid bacilli may penetrate in the soil, the experiments of Grancher and Deschamps show that at the end of five weeks they may reach a depth of 16 to 20 inches below the surface. As Hoffmann has demonstrated the extraordinary slowness with which fluids and fine particles penetrate the soil, it is probable that in the course of time a greater depth than this may be reached. Indeed, Macé claims to have found in the neighborhood of a wall, suspected of infection, typhoid bacilli, together with ordinary intestinal bacteria, at a depth of at least $61 / 2$ feet below the surface. There are a number of instances recorded in which there is good reason to believe that turning up the soil and cleaning out privies or dung-heaps in which typhoid stools have been thrown, have given rise to typhoid fever, even after the infectious excreta have remained there a year and more.

It cannot be said that bacteriological investigations have as yet shed much light upon a factor which plays a great rôle in epidemiology, namely, predisposition to infection from the ground, according to locality and time, and this deficiency receives constant and veliement emphasis from the localistic school of epidemiologists. We can, however, readily understand that varying conditions, such as temperature, moisture, porosity, quality of soil may exert a controlling influence in determining the behavior of infectious germs in the soil and the facility of their transportation to human beings or animals. As regards that much-discussed question, the significance of variations in the height of the subsoil water, in relation to the prevalence of certain epidemic diseases, particularly cholera and typhoid fever, we now know that this cannot depend upon the presence of bacteria in the subsoil water itself or in the capillary layers immediately above it. It has been plausibly suggested that with the sinking of the subsoil water fluids from infected cesspools, privy vaults, and other localities may more readily be drawn into wells or other sources of water- supply, and that by the same cause the surface of the ground becomes dry, so that dust particles may be lifted by the wind. Other more or less plausible explanations have also been offered, but it must be confessed that our positive information on this point is meagre. There can, however, be little doubt that this significance of the variations in subsoil water is apparent only for certain localities and has been considerably exaggerated and often misunderstood. It is not, however, pertinent to my theme to discuss this or other purely epidemiological observations concerning the relations of the ground to the spread of epidemic diseases, interesting and important as are many of these observations.

Before leaving the subject of the ground as a source of infection, permit me to indicate briefly some conclusions which may be drawn from what has been said as to the principles which should guide us in preventing infection directly or indirectly from the ground.

First in importance is to keep infectious substances, so far as possible, from the ground. This implies the early disinfection or destruction of such substances as typhoid and cholera excreta and tuberculous sputum.

Second. The ground should be rendered, so far as practicable, unsuitable for the continued existence of infectious germs. This, at least for some diseases, is accomplished by a proper system of drainage, which, moreover, for other reasons possesses hygienic importance.

Third. Means should be provided to prevent waste products from getting into the ground around human habitations or from gaining access to water used for drinking or domestic purposes. In cities this can be accomplished only by a properly constructed system of sewers. The system of storing waste products in cesspools, whence they are to be occasionally removed cannot be approved on hygienic grounds. There are conditions in which the disposal of waste products in deep wells only used for this purpose and whence these products can filter into the deep layers of the ground may be permissible, but this can never be considered an ideal method of getting rid of excrementitious substances and is wholly wrong in regions where wells are used for drinking water. But I am trespassing with these remarks upon a province which does not belong to me, but rather to practical sanitarians and engineers. I shall only add that the advantage gained by preventing organic waste from soaking into the ground is not so much that the ground is thereby rendered better adapted for the existence of infectious microörganisms, but is due rather to the fact that this waste is likely to contain infectious germs.

Finally, in cities good pavements, absence of unnecessary disturbance of the soil, cleanliness of the streets and laying of the dust by sprinkling are not only conducive to comfort but are some- 
times hygienically important in preventing infection from the ground and dust.

In passing from the consideration of the ground to that of water one feels that he now has to do with a possible source of infection against which in this country and in England he is at liberty to make any accusation he chooses without fear of contradiction. There is reason to believe that such accusation has been repeatedly made without any proof of misdemeanor on the part of the water. It is not, therefore, with any desire to awaken further the medical or public conscience that I wish to say a few words concerning the behavior of bacteria in water and the dangers of infection from this source. That such dangers are very real must be apparent when we consider the universal employment of water and its exposure to contamination from all kinds of sources.

Ordinary water, as is well known, contains bacteria in large number. Not a few species of bacteria can multiply rapidly and to a large amount even in distilled water. These are socalled water-bacteria, and like most of the microorganisms found in ordinary drinking water are perfectly harmless saprophytes. What we wish to know is, how pathogenic microörganisms conduct themselves in water. Can they grow or be preserved for any length of time in a living condition in water? As regards the multiplication of pathogenic bacteria in water the results of different experimenters do not altogether agree. Whereas Bolton failed to find any growth, but rather a progressive diminution in number of pathogenic bacteria planted in sterilized water, Wolff hügel and Riedel observed a limited reproduction of such bacteria, including those of typhoid fever and of cholera. This difference is due probably to the methods of experimentation employed. According to Kraus, these latter bacteria diminish rapidly in number in unsterilized spring or well water kept at a low temperature. These experiments indicate that water, even when contaminated with more organic impurities than are likely ever to be present in drinking water, is not a favorable breeding place for pathogenic bacteria. Still it is to be remembered that these laboratory experiments do not reproduce exactly all of the conditions in nature, and it may happen that in some nook or cranny or vegetable deposit at the side of a well or stream some pathogenic bacteria may find suitable conditions for their multiplication.

But, as has been repeatedly emphasized in this address, it is not necessary that pathogenic bacteria should actually multiply in a medium in order to render it infectious. It is sufficient if their life and virulence are not destroyed in a very short time. As to this important point, Bolton found that in sterilized water typhoid bacilli may preserve their vitality for over three months and cholera bacteria for eight to fourteen days, while
Wolff hiigel and Riedel preserved the latter in water for about eighty days. Under natural conditions, however, these organisms are exposed to the overgrowth of the water bacteria, so that Kraus found in unsterilized water kept at a temperature of $10.5^{\circ} \mathrm{C}$. the typhoid bacilli no longer demonstrable after seven days, and the cholera bacteria after two days. The conditions in Kraus's experiments were as unfavorable as possible for the continued existence of these pathogenic bacteria, more unfavorable than those often present at the season of prevalence of cholera and typhoid fever, neverthless I do not see that they justify the conclusions of Kraus as to the slight probability of drinking water ever conveying infection with the germs of typhoid fever and of cholera. To render such a conclusion probable it would be necessary to demonstrate a much shorter preservation than even Kraus himself found. In judging this question it should not be overlooked that infection of drinking water with the typhoid or the cholera germs is not so often the result of throwing typhoid or cholera stools directly into the source of water-spipply as it is the consequence of leaky drains, cesspools, privy-vaults or infected soil, so that there may be continued or repeated accessions of infected material to the water.

In view of the facts presented, there is no sufficient reason, therefore, from a bacteriological point of view, of rejecting the transmissibility of typhoid fever and cholera by the medium of drinking water. This conclusion seems irresistible when we call to mind that Koch once found the cholera bacteria in large number in the water of a tank in India, and that the typhoid bacilli have been repeatedly found in drinking water of localities where typhoid fever existed. Nor do I see how it is possible to interpret certain epidemiological facts in any other way than by assuming that these diseases can be contracted from infected drinking water, although I know that there are still high authorities who obstinately refuse to accept this interpretation of the facts.

In this connection it may be mentioned that pathogenic bacteria may preserve their vitality longer in ice than in unsterilized drinking water. Thus Prudden found typhoid bacilli still alive which had been contained in ice Io 3 days.

When we come to consider the ways in which water may become infected with pathogenic microörganisms we recognize at once a distinction in this respect between surface water and subsoil water. Whereas the subsoil water may be regarded under ordinary circumstances and in most places as germ-free, the surface water, such as that in rivers and streams, is exposed to all manner of infection from the ground, the air, and the direct admission of waste substances. Unfortunately in the ordinary way of obtaining subsoil water for drinking purposes by means of dug wells this distinction is obliterated, for the water 
which enters these wells free from bacteria is converted into a surface water often exposed, by the situation of the well, to more dangerous contamination than other surface waters used for drinking purposes.

Now let us turn our attention, as we have done with other sources of infection, to a brief outline of certain general principles which may help us in avoiding infection from the water.

We shall in the first place avoid so far as possible the use of water suspected of infection, especially with the germs of such diseases as typhoid fever and cholera. When it is necessary to use this susperted water it should be boiled.

As regards the vital question of water-supply, it may be stated as a general principle that no hygienic guarantee can be given for the purity of surface water which has not been subjected to a proper system of filtration, or for the purity of spring or well water fed from the subsoil, unless such water is protected from the possibility of infection through the upper layers of the soil or from the air. This is not saying that water which meets certain chemical and biological tests and which is so situated that the opportunities for its contamination appear to be absent or reduced to a minimum is not admissible for the supply of drinking water, but the possibility of infection can be removed only by the fulfillment of the conditions just named, and upon these conditions the hygienic purist will always insist.

Unfortunately we have at present no domestic filters which are satisfactory, and most of those in common use are worse than none, as they soon furnish a filtrate richer in bacteria than the orig. inal water. The only effective method of waterfiltration for the general supply is by means of large sand filters, such as are in use with excellent results in Berlin and some other cities. These require skilled attention. I cannot on this occasion discuss the construction or working of these filters, but would refer those who are interested to the full and careful investigation of the Berlin filters by Wolff hïgel and by Plagge and Proskaver.

What is accomplished by these artificial sand filters is accomplished under natural conditions, also by the ground, which furnishes a subsoil water free from microörganisms, and to obtain pure water we have only to devise means by which this subsoil water may be secured without the chance of contamination. Just as the water which has passed through the sand filters is collected in suitable reservoirs and is distributed in pipes, which do no not admit contamination from without, so by means of properly constructed artesian or driven wells we may secure the naturally filtered subsoil water with the same freedom from the chances of infection.

It is well to bear in mind that no biological or chemical tests of water can replace those measures which have been mentioned as necessary to secure purity of water-supply. These tests are of value only when applied with proper precautions and with due consideration of the special circumstances of each case for which they are employed. There has been much profitless discussion as to whether greater significance is to be attached to the chemical or to the bacteriological examination of water. Each has its own special field of application and in this the one cannot replace the other method. The bacteriological examination has for hygienic purposes the advantage that it may enable us to detect the specific agents of infection in the form of microörganisms, as has already been done for cholera bacteria and typhoid bacilli, but this is a comparatively rare result and does not at present afford a wide field of application for this method. The significance of the bacteriological test is to be based more frequently upon the fact that it concerns itself with the same class of microörganisms to which some of the recognized and doubtless many of the undiscovered infectious agents belong and from the behavior of which in some respects conclusions can be drawn as to the behavior of the pathogenic organisms. Thus the bacteriological test is the only one which enables us to judge correctly of the efficacy of those methods of filtration of surface water and of construction of wells which insure purity of water-supply. The points of view from which we can estimate correctly according to our present knowledge the relative merits and fields of application of the chemical and of the bacteriological methods of water examination have been clearly indicated by Plagge and Proskauer, and by Wolffhiigel. The theme is one beyond the limits or the scope of this discourse and I have referred to it chiefly to emphasize the fact that we cannot rely upon chemical or bacteriological tests of water to the exclusion of those protective measures which have been mentioned, although I do not intend to imply that each of these tests when properly employed does not afford important information and is not of great value in many cases.

I have already taxed so largely your time and patience that I must pass over with brief mention the food as a source of infection. Unlike those external sources of infection which we have hitherto considered, many articles of food afford an excellent nutritive medium for the growth of a number of species of pathogenic microörganisms, and in many.instances this growth may be abundant without appreciable change in the appearance or taste of the food.

When we consider in how large degree the certainty and the severity of infection with many kinds of pathogenic microörgaisms depend upon the number of such organisms received into the body, we can appreciate that the danger of infection from food which contains a mass of growing 
pathogenic bacteria may be much greater than that resulting from the reception of infected water or aid, media in which infectious organisms are rarely present in other than a very dilute condition. The entrance into the body of a single infections bacterium with the inspired air is, at least in the case of many diseases, not likely to cause infection, but let this bacterium fall upon some article of food, as ior instance upon milk, where it can multiply in a short time at a favorable temperature many thousand-fold and evidently the chances of infection become vastly increased.

Among the various agencies by which infectious organisms may gain access to the food may be mentioned the deposition of dust conveyed by the air, earth adhering to vegetables, water used in mixing with or in the preparation of food, in cleansing dishes, clothes, etc., and contact in manifold other ways with infected substances.

Fortunately a very large part of our food is sterilized in the process of cooking shortly before it is partaken, so that the dangers of infection from this source is greatly diminished and comes into consideration only for uncooked or partly cooked food and for food which, altnough it may have been thoroughly sterilized by heat, is allowed to stand a considerable time before it is used. Milk, in consequence of its extensive employment in an unsterilized state and of the excellent nutritive conditions which it presents to many pathogenic bacteria, should be emphasized as especially liable to convey certain kinds of infection; a fact supported not less by bacteriological than by clinical observations. Hesse found that also a large number of ordinary articles of food prepared in the kitchen in the usual way for the table and then sterilized afford a good medium for the growth and preservation of typhoid and cholera bacteria, frequently without appreciable change in the appearance of food.

Upon solid articles of food bacteria may multjply in separate colonies, so that it may readily happen that only one or two of those who partake of the food eat the infected part, whereas with infected liquids, such as milk, the infection is more likely to be transmitted to a larger number of those who are exposed.

In another important particular the food differs from the other sources of infection which we have considered. Not only the growth of infectious bacteria, but also that of bacteria incapable of multiplication within the body may give rise in milk and other kinds of food to various ptomaines, products of fermentation and other injurious substances which when injested are likely to cause more or less severe intoxication or to render the alimentary tract more susceptible to the invasion and multiplication of genuinely infectious organisms.

It is plain that the liability to infection from food will vary according to locality and season.
In some places and among some races the proportions of uncooked food used is much greater than in other places and among other races. In general in summer and in autumn the quantity of fruit and food ingested in the raw state is greater than at other seasons, and during the summer and autumn there is also greater danger from the transportation of disease germs from the ground in the form of dust, and the amount of liquids imbibed is greater. The elements of predisposition according to place and time upon which epidemiologists are so fond of laying stress are not therefore absent from the source of infection now under consideration.

I have thus far spoken only of the secondary infection of food by pathogenic microörganisms, but as is well known the substances used for food may be primarily infected. Chief in importance in the latter category are the variousentozoa and other parasites which infect animals slaughtered for food. The dangers to mankind resulting from the diseases of animals form a separate theme, which would require more time and space than this address affords for their proper consideration. I shall content myself on this occasion with only a brief reference to infections from the milk and flesh of tuberculous cattle.

It has been abundantly demonstrated by numerous experiments that the milk from tuberculous cows is capable when ingested of causing tuberculosis. How serious is this danger may be seen from the statistics of Bollinger, who found with cows affected with extensive tuberculosis the milk infections in 80 per cent. of the cases, in cows with moderate tuberculosis the milk infections in 66 per cent. of the cases, and in cows with only slight tuberculosis the milk infections in 33 per cent of the cases. Dilution of the infected milk with other milk or with water diminished or in sufficient degree it removed the danger of infection. Bollinger estimates that at least 5 per cent. of the cows are tuberculous. From statistics furnished me by Mr. A.W. Clement, V. S., it appears that the number of tuberculous cows in Baltimore which are slaughtered is not less than 3 to 4 per cent. Among some breeds of cattle tuberculosis is known to be much more prevalent than this.

There is no evidence that the meat of tuberculous cattle contains tubercle bacilli in sufficient numbers to convey infection, unless it be very exceptionally. Nevertheless one will not willingly consume meat from an animal known to be tuberculous. This instinctive repugnance, as well as the possibility of post-mortem inspection of the meat in dressing the animal seem good grounds for discarding such meat. The question, however, as to the rejection of meat of tuberculous animals has important economic bearings and has not been entirely settled. As to the rejection of the milk from such animals, however, there can be no difference of 
opinion, although this is a point not easily controlled.

The practical measures to adopt in order to avoid infection from the food are for the most part sufficiently obvious. Still it is not to be expected that every possibility of infection from this source will be avoided. It is difficult to discuss the matters considered in this address without seeming to pose as an alarmist. But it is the superficial and half knowledge of these subjects which is most likely to exaggerate the dangers. While one will not under ordinary circumstances refrain from eating raw fruit or food which has not been thoroughly sterilized, or from using unboiled or natural waters in the fear that he may swallow typhoid or cholera bacteria, still in a locality infected with cholera or typhoid fever he will, if wise, not allow himself the same freedom in these respects. Cow's milk, unless its source can be carefully controlled, should, when used as a habitual article of diet, as with infants, be boiled, or the mixed milk of a number of cows should be selected, but this latter precaution offers less protection than the former.

In most places in this country we are sadly lacking in good sanitary inspection of the food, especially of the animal food, offered for sale. One cannot visit the slaughter-house in Berlin or Munich, and doubtless similar ones are to be found elsewhere, and watch the intelligent and skilled inspection of slaughtered animals without being impressed with our deficiency in this respect. In large cities an essential condition for the efficient sanitary inspection of animal food is that there should be only a few places, and preferably only one place, where animals are permitted to be slaughtered. Skilled veterinarians should be selected for much of the work of inspection.

It may reasonably be asked that the National Government, which has already spent so much money for the study and extermination of such diseases as pleuro-pneumonia, of cattle, and hog cholera, which are not known to endanger the life of human beings, should turn its energies also to means for eradicating tuberculosis from cattle, which is a scourge not only to the economic interests of farmers and dairymen, but also to the health of human beings.

Without any pretension to having done more in this address than to sketch here and there a few principles derived from bacteriological researches concerning only some of the most widely distributed external sources of infection, I trust that enough has been said to show the folly of any exclusive dogma as to modes of infection. The ways of infection, even in one and the same disease, are manifold and various, and can never be resolved into exclusive hypotheses, such as the drinking-water hypothesis, the ground hypothesis, etc.
It follows, therefore, that it is not by sanitary improvements in one direction only that we can control the spread of preventable epidemic diseases. In one situation the improvements in the supply of drinking water check the prevalence of typhoid fever, in another place similar measures show no such influence; or again, in one city the introduction of a good system of sewerage dimin. ishes epidemic diseases, and in another no similar result follows. We should, therefore, aim to secure so far as possible good sanitary arrangements in all directions and in all respects.

It has also been rendered evident in what has been said that infectious agents differ markedly from each other in their behavior, so that while public sanitation aims at those measures which are found to be most widely beneficial, it should not forget that each infectious disease is as much a separate problem in its prophylaxis as in its symptomatology, etiology and treatment. It will not aim to combat cholera with the means found best adapted to scarlet fever, but it will adopt preventive measures as directly to the specific end in view as possible.

In presenting to you the results of researches chiefly bacteriological concerning the scientific basis of preventive medicine, I hope to escape the accusation of onesidedness and narrowness by the statement that I do not for a moment intend to imply that the bacteriological method is our only source of accurate knowledge on the subjects which have been considered. My aim is accomplished if $I$ have succeeded in making clear that this method has established facts which aid in a clearer conception of the causes of some important infectious diseases, in a better understanding of the sources and danger of infection, and in a wore efficient selection and application of sanitary measures.

If this science of only a few years' growth has furnished already acquisitions to knowledge so important, so far reaching, may we not look forward with assurance to the solution of many dark problems in the domain of infectious diseases, problems the solution of which may yield to preventive medicine a future of usefulness and success which we cannot now foresee.

Dr. Philip F. BRAkELY, who for forty years was the Secretary of the Medical Society of Warren County, N. J., died in Belvidere, at the age of 75 , on July 3 . He was a representative man in northern New Jersey, just as Dr. Wm. Elmer, who died six days before him, was an able standard bearer in the southern section of the State. Dr. Brakely was early identified with the American Medical Association, and a permanent member of the State Society. His death has been ascribed to the infirmities of advancing age, culminating in cardiac syncope. 